authors discuss the apparent excess of intellectual disability among Aborigines, which may be exacerbated by their cultural dislocation and consequent loss of their traditional relationship to the land and nature. Their history of appalling treatment by settlers from Europe has resulted in a cultural limbo, with high rates of drug and alcohol misuse, which fosters developmental disorders in the children of users. There are no culturally appropriate ways of measuring 'intelligence' in a people for whom the Western way of relating to the world is completely alien. This is a very thought-provoking essay on an important and neglected subject.
Finally, Dr Allen-Leigh and colleagues from Mexico present a qualitative account of the way in which adults with intellectual disability are benefiting from recently developed services that are designed to encourage their sense of independence and self-efficacy. This has come about in part through changes in societal attitudes and in part because of new legislation. Their conclusion, that it is particularly important to combine practical training with services to support greater social inclusion for people with intellectual disabilities, is applicable to all regions represented by these articles.

\title{
Intellectual disability in India: the evolving patterns of care
}

\section{Satish Chandra Girimaji MD}

Professor, Department of Child and Adolescent Psychiatry, National Institute of Mental Health and Neuro Sciences (NIMHANS), Bangalore, India, email girimaji@nimhans.kar.nic.in

\begin{abstract}
ntellectual disability was recognised in ancient Indian literature, but organised services have a history of just five decades. India shares many features of low- and middleincome (LAMI) countries regarding intellectual disability. There is a low level of awareness about its nature, causes and interventions. One can come across many superstitions, myths and misconceptions about intellectual disability. In general, services are inadequate, being concentrated in big cities and urban areas. There is generally limited access to support services and few government benefits, and these, in any case, are often of little value (World Health Organization, 2007). Locally and nationally, there are few relevant and reliable epidemiological data on the prevalence of intellectual disability. However, there have been some positive developments within the past three decades, and they are the focus of this paper.

The limited epidemiological data in India on intellectual disability suggest a prevalence of around $2-2.5 \%$ in the general population. An excess prevalence in males, rural areas and low-income groups is reported. Acquired causes account for about $30 \%$ of cases. It is estimated that at least $25 \%$ of intellectual disability is preventable in India (Srinath \& Girimaji, 1999).
\end{abstract}

\section{Legislation}

The first attempt by the central government to provide legislation for people with disability resulted in the Persons with Disabilities Act 1995, an Act that emphasised equality of opportunity and non-discrimination, together with the range of services that needed to be developed, such as prevention, early intervention, education, training and social benefits. This Act is currently undergoing revision to bring it in line with the United Nations Convention on the Rights of Persons with Disabilities. Both central and state governments have introduced many social justice measures such as disability pensions, family pensions, travel concessions, income tax exemption and health insurance, but, as noted above, limited access to the benefits and the extent of utilisation are causes for concern.

Later legislation that specifically addressed those with intellectual disability included the National Trust Act 1999 for persons with 'mental retardation', cerebral palsy, autism and multiple disabilities. This Act was intended to empower persons who could not speak for themselves, as well as their families. It was envisaged that it would permit greater participation of parents' associations (see below) and nongovernmental organisations (NGOs) in service development. Subsequent Acts, policies and issues, including progress in research and in human resources, have been reviewed elsewhere (Girimaji \& Srinath, 2010). One notable development has been a remarkable growth in the number of professionals trained in special education (Narayan, 2007).

\section{Services}

India has many prevention and promotion programmes that concern intellectual disability. These include integrated child development services as well as reproductive and child health services. Their main focus is on health education, health promotion during pregnancy, optimum perinatal care, childhood nutrition, immunisation and, to some extent, early detection and intervention.

A recent and widely acclaimed programme is the National Rural Health Mission. Of great interest is the role of 'accredited social health activists'. These are women from the local 
community who are paid to educate rural folk and bring them into contact with services. Their roles include booking clinic appointments for pregnant women, bringing them for periodic checkups, ensuring hospital-based delivery and bringing sick children to hospital for care.

Clinical services for intellectual disability are inadequate and unevenly distributed. They include: clinical evaluation, physical and psychological testing, parent counselling, treatment of comorbid physical and mental disorders, and genetic counselling. Mental hospitals, general hospital psychiatric units, paediatric clinics and a handful of child guidance clinics and intellectual disability clinics provide some mental health services. There are a few referral centres that provide good-quality care; they also undertake some professional training and research.

\section{Families and family-focused intervention}

The closely knit kinship systems in India have always cared for their members with intellectual disability. Institutionalisation, unlike in the West, has never been a major movement in India and a very small proportion of the population with intellectual disability lives away from home. Families generally take care of their needy relatives with compassion, because of a sense of duty. This does not mean that they do not suffer; studies have demonstrated that families experience high levels of stress because of the care burden upon family members, especially mothers (Girimaji et al, 1999). There may be a negative impact on the family's quality of life, as well as that of the affected individuals, because of the lack of adequate support services. Recent social changes in terms of globalisation, urbanisation and Westernisation may have, to some extent, eroded the capacity of families to cope in these circumstances.

In the 1980s and 1990s, professionals working with intellectual disability started exploring the possibility of involving families in management. They were successful in training parents to use behaviour modification techniques and in teaching self-help skills. The approach has now found widespread application, albeit with wide variations in goals and approaches (Russell et al, 1999; Girimaji, 2003), affirming the strength of parent-professional partnerships. A National Trust Act grant now funds training programmes for informal caregivers.

\section{Community-based rehabilitation initiatives in India}

One can trace three or four decades of community orientation in the organisation of services for people with intellectual disability in India. This developed initially from outreach services, satellite clinics and camps run by centres that were already providing some support to that population, but which felt the need to extend their involvement, driven by the philosophy of 'reaching the unreached'. Those centres also engaged in the training of workers at the grassroots level.

The initial focus of community-based rehabilitation (CBR) was on highly 'visible' impairments such as locomotor disability, blindness and deafness. However, within the past two decades intellectual disability has been included on the CBR agenda, an extension initiated by NGOs with strong community links and, later, by governmental agencies. One example is the establishment of district disability rehabilitation centres (DDRCs). An interesting feature of DDRCs is that at least one grass-roots worker must be a person with a disability, called vikalang bandhu.

Typical activities in CBR programmes include: improving community awareness and attitudes; reducing social isolation and enhancing community participation; helping individuals and their families to access services and benefits; transferring skills to families for home-based training programmes; and improving school enrolment.

There is no doubt that the CBR approach holds promise, with the participation of a trained grass-roots worker as the key professional. By way of example, a 10-year-old boy with severe intellectual disability was never taken out of the house, as his mother feared he would have a recurrence of his seizure on exposure to the wind, but also because she felt ashamed of having a handicapped child. A CBR worker visited her at home, counselled her and initiated the child's socialisation by convincing the mother to take him to the village temple. This visit succeeded because the CBR worker accompanied her. The outing provided a turning point in the boy's and family's life, and reduced the social consequences of his disability.

\section{Parents' associations}

The parental self-help movement has its origins in 1981, with a workshop held in Bangalore (sponsored by the World Health Organization and the Indian National Institute of Mental Health and Neuro Science) and it has seen remarkable growth. Currently, there are more than 180 parents' associations and the number is growing. These associations have formed an umbrella organisation, Parivaar (a Sanskrit word meaning 'extended family'). They play an increasing role in advocacy, awareness, the organisation of services, participation in legislative initiatives and policy-making, and the implementation of relevant policies and programmes (see www.parivaarnfpa.org).

\section{Education and training}

Special schools for children with intellectual disability were first organised in India over five decades ago. They are mostly run by NGOs, with or without the support of public funds. They started in large metropolitan areas, but later spread to smaller cities and towns. Their number has seen a phenomenal growth in the past decade and there are now more than 1200 such schools all over India.

The government of India recently endorsed the philosophy of inclusive education and has started the 'Education for all 6- to 14-year-olds' programme ('Sarva Shiksha Abhiyan'). This follows a zero-rejection policy, which means that all children - regardless of any type or degree of disability - should receive appropriate education, preferably within regular schools or through education at home from specially trained teachers. This programme has witnessed considerable growth in recent years. A further development has been the enactment of the new Right to Education Act. 
Services for adults with intellectual disability are still relatively undeveloped. Vocational training and job placement services are hard to find, even in metropolitan areas. There is some potential for the employment of people with intellectual disability in rural, agriculturally based economic activities, but this arrangement needs further exploration and consolidation.

\section{Conclusions}

Currently in India, there is a mosaic of services for people with intellectual disability. Within recent years innovative approaches for the better management of these conditions in childhood have emerged, including parents' associations, family-focused interventions and CBR programmes. Families continue to be a major source of care, but they are in need of many additional services and support. Landmark legislation to recognise and address the problem has been passed but it still requires full implementation. We anticipate a stronger, rights-based approach to service development in the years to come.

\section{References}

Girimaji, S. R. (2003) Family focused intervention in mental retardation Indian models. In Changing Marital and Family Systems: Challenges to Conventional Models in Mental Health (eds R. S. Bhatti, M. Varghese \& A. Raguram), pp. 192-199. National Institute of Mental Health and Neuro Science.

Girimaji, S. C. \& Srinath, S. (2010) Perspectives of intellectual disability in India: epidemiology, policy, services for children and adults. Current Opinion in Psychiatry, 23, 441-446.

Girimaji, S. C., Srinath, S., Seshadri, S. P., et al (1999) Family Interview for Stress and Coping in Mental Retardation (FISC-MR): a tool to study stress and coping in families of children with mental retardation. Indian Journal of Psychiatry, 41, 341-349.

Narayan, J. (2007) Intellectual disabilities in India. Presented at the Second International Conference on Intellectual Disabilities/Mental Retardation, Bangkok, 16 February. See http://www.bangkok-id-conference.org/pdf/intellectual-disabilities-in-india (accessed March 2011).

Russell, P. S. S., John, J. K. \& Lakshmanan, J. L. (1999) Family intervention for intellectually disabled children. Randomised controlled trial. British Journal of Psychiatry, 174, 254-258.

Srinath, S. \& Girimaji, S. R. (1999) Epidemiology of child and adolescent mental health problems and mental retardation. NIMHANS Journal, 17, 355-366.

World Health Organization (2007) Atlas of Global Resources for Persons with Intellectual Disabilities. WHO.

\title{
Intellectual disability and Aboriginal Australians - training needs for psychiatrists
}

\author{
Meera Roy ${ }^{1}$ and Sivasankaran Balaratnasingam ${ }^{2}$ \\ ${ }^{1}$ Consultant in Psychiatry of Learning Disability, South Birmingham Primary Care Trust, UK, email Meera.Roy@sbpct.nhs.uk; \\ ${ }^{2}$ Assistant Professor and Regional Psychiatrist, Kimberley Mental Health and Drug Service, Broome, Western Australia
}

\begin{abstract}
boriginal Australians have relatively high rates of intellectual disability, a situation that is probably due mainly to poor health and social disadvantage. Populations with high rates of intellectual disability are more at risk of developmental disorders and mental ill health. We explore the training needs for psychiatrists working with indigenous people and how they can be met.

Aboriginal Australians are the original inhabitants of the Australian continent and nearby islands. Together with the Torres Strait Islanders, they form $2.7 \%$ of the population. Aboriginal communities are diverse, with different languages and cultural practices. Historically, they were a semi-nomadic hunter-gatherer people. Each clan possessed specific territory, defined by geographical features such as rivers and mountains. They shared an intimate understanding of and relationship with the land, and that relationship was
\end{abstract}

underpinned by 'dreamtime' stories, a set of beliefs that is fundamental to their well-being. An Aboriginal person attains status by acquisition of knowledge (especially about the land) rather than by acquiring material possessions. Traditional Aboriginal society is structured by social and family systems, which organise all aspects of life and perception.

The British colonisation of Australia was a catastrophic event for the Aboriginal people. Disease, displacement and direct violence from the settlers reduced the Aboriginal population by $90 \%$ between 1788 and 1900. The settlers also introduced alcohol, and alcohol misuse played a major role in further destroying Aboriginal social structures. Between 1869 and 1969 Aboriginal children were removed from their parents by federal and state agencies and church organisations, and brought up within a 'white' culture, on such disparate grounds as child protection and maintenance of 